Doi: HTTPS://DOI.ORG/10.23910/2/2020.0361

\title{
A Review on Terminalia chebula Retz. (Harar)- An Important Multipurpose Tree
}

\author{
Samanpreet Singh ${ }^{1}$, Avinash Kumar Bhatia ${ }^{2 *}$, Kamal Sharma² and Dushyant Sharma ${ }^{2}$
}

${ }^{1}$ College of Forestry, Dr. Y.S. Parmar University of Horticulture and Forestry, Nauni, Solan, H.P. (173 230), India

${ }^{2}$ College of Horticulture and Forestry, Dr. Y.S. Parmar University of Horticulture and Forestry, Neri, Hamirpur, H.P. (177 001), India

\section{Corresponding Author}

Avinash Kumar Bhatia

e-mail: avinashgolu1997@gmail.com

\author{
Article History \\ Article ID: IJEP0361 \\ Received in 02 ${ }^{\text {nd }}$ March, 2020 \\ Received in revised form $15^{\text {th }}$ March, 2020 \\ Accepted in final form $19^{\text {th }}$ March, 2020
}

\begin{abstract}
Terminalia chebula Retz. commonly known as 'Harar' belongs to the family Combretaceae. It is found in deciduous forests throughout the greater part of India, China, Myanmar, Sri Lanka, Vietnam, Bangladesh, etc. In India, it is distributed throughout the greater part except in arid zones. The fruits are common constituent of 'Triphala', capable of imparting youthful vitality and receptivity of mind and sense and are extensively used for clinical research, tanning and furniture purposes and also contain $1.73 \%$ nitrogen and $2.75 \%$ Calcium. The demand for its fruit has increased tremendously, because of its medicinal value; its fruits are sold at a price of ₹ $10-60 \mathrm{~kg}^{-1}$. However, the poor germination capacity, lack of natural regeneration and knowledge regarding its propagation are the limiting factors for its adoption in agroforestry systems. There is need of more productive planting stock with lower juvenile period and comparatively large fruit size.
\end{abstract}

Keywords: Agroforestry, deciduous, juvenile, propagation

\section{Introduction and Socio-economic Importance}

Terminalia chebula is one of the very important indigenous multi-purpose tree species and is commonly known as Harar, Harra, Hirda, Myrobalan and Haritaki (Burkill, 1985). It is however, called the "king of medicines". The fruits of the species are used locally in many medicines and are an important constituent of 'Triphala' and commercially used in many Ayurvedic medicines to treat heart burn, flatulence, dyspepsia, liver and spleen disorders, asthma and constipation. There are various companies that use harar for making their various products like Himalaya, Dabur, Organic India, Kapiva, Baidyanath, etc. Apart from medicinal and clinical uses, myrobalans are also used in the preparation of ink and in dye as a mordant for the basic aniline dyes and the fruit is extensively used for tanning. The wood is used for building purposes, agricultural implements, plywood and in match box industry. It is also grown as a shade tree (Joy et al., 1998; Joshi, 2002; Khare, 2007 and Trivedi, 2008), also for cabinet work, furniture and interior fitting (Sambamurty, 2005). This plant is also used as fodder (Kumar and Bhatt, 2006). In some states of India and some countries from gulf like Arabic, Afghanistan and Pakistan, fruit jam is used as food supplement.

\section{Distribution and Growth Behavior}

Terminalia chebula Retz. occurs typically in dry deciduous forests and favoring clay soil, up to $1450 \mathrm{~m}$ in southern India, $450 \mathrm{~m}$ in Central India, $200 \mathrm{~m}$ in Western India, 500 $\mathrm{m}$ in North East India and $1500 \mathrm{~m}$ in Himalaya. In its natural habitat, it occurs at an elevation of 500-1500 m where the mean maximum temperature in its habitat varies from $37^{\circ} \mathrm{C}$ to $48{ }^{\circ} \mathrm{C}$, absolute minimum temperature from $1{ }^{\circ} \mathrm{C}$ to $15^{\circ} \mathrm{C}$ and annual rainfall from 750 to $3250 \mathrm{~mm}$ (Joshie and Narain, 1992). It is also found in sub Himalayan tract from the Ravi eastward to West Bengal and Assam. It is found on variety of geological formations and on laterite, clayey as well as sandy soil. The species is a strong light demander, frost-hardy and drought resistant to a considerable extent. It coppices very well, the coppice-shoots being often very vigorous. T. chebula does not suffer from pollinator limitation to maximize fruit set but from the limitation of compatible pollen and flower (Sankanur et al., 2015).

\section{Chemical Properties}

Terminalia chebula is a rich source of tannin (27.3-40.0\%) which varies with genotype and geographical location. The chief constituents of tannin are chebulic acid, chebulagic acid, corrilagin and gallic acid. Besides these, amino acids, succinic acid, betasitosterol, resin and purgative principles of anthroquinone and sennoside nature are also present. The leaves contain $1.73 \%$ nitrogen (equivalent to $10.80 \%$ protein content) and $2.75 \%$ Calcium (Singh, 1982). It also 
consists of nutrients such as vitamin C, protein, amino acids and minerals (Mahesh et al., 2007). Some carbohydrates are also present like glucose, sorbitol, fructose and sucrose. Other important constituents include phenolics such as chebulinic acid, ellagic acid and anthraquinones. Some of the other minor constituents are polyphenols such as corilagin, galloyl glucose, punicalagin, terflavin A, terflavin B, maslinic acid, etc. In clinical trials, the fruit of $T$. chebula is reported to be hepatoprotective (Tasduq et al., 2006), anti-hyperlipidimic (Israni et al., 2010), anti-arthritic (Nair et al., 2010), antihelmintic (Dwivedi, 2008), immune modulator (Aher and Kumar, 2010), antibacterial (Bag et al., 2009), cardioprotective (Reddy et al., 1990), antimutagenic, anticarcinogenic (Reddy et al., 2009; Saleem et al., 2010), anti-HIV (Ahn et al., 2002) and antidiabatic (Kannan et al., 2012). The observed health benefits may be credited to the presence of the various phytochemicals like polyphenols, terpenes, anthocyanins, flavonoids, alkaloids and glycosides. Fruits are used for diabetes, fever and anemia (Daniel, 2005).

\section{Propagation}

The effect of different harvesting time and seed treatments on seed germination, variation in fruit characteristics, and effect of sizes of root stock (diameter) and methods of grafting on sprouting success and growth of the seedlings was investigated by Saleem et al. (2013). The seeds collected from mid January till mid March resulted in statistically significant higher germination than those collected from mid November to January beginning. Mechanical breaking of seed coat resulted in the highest germination (73.6\%) which was significantly higher than all other pre-sowing treatments. Vegetative propagation has been found advantageous over seed propagation as the former technique reduces the juvenile period and subsequently facilitates early maturing. Three grafting methods (cleft, tongue grafting and patch budding) were tested by Sharma et al. (1995) using scion material from a $T$. chebula tree selected in Himachal Pradesh for its superior fruit (the fruits are used medicinally) and 4 year old stock plants of $T$. chebula and $T$. belerica. Only the patch budding method was successful, with growth starting 45 days after grafting, and producing $18 \mathrm{~cm}$ sprouts within 3 weeks, in contrast to seedlings which grew to 15-20 $\mathrm{cm}$ in 7 months. The natural regeneration of $T$. chebula by seed is poor due to its hard mesocarp, thick shell and poor formation of kernel and vegetative propagation through quite successful, requires juvenile period for fruiting. To overcome time difficulty its cleft grafting was tried and was successful in getting good graft plants in good time. These were also well branched, gave suitable branchlet for approach grafting which was also very successful and opens new horizon's for the formation of a clonal bank for this species. This new technology will also help farmers in obtaining sustained income gains as well (Srivastava, 2000).

\section{Insect-Pests}

Uredo terminaliae causes leaf rust disease on clonal plants of Terminalia chebula in the research nursery of State Forest Department, Coimbatore (Mohan and Manokaran, 2005). The disease started appearing during the month of November. Very severe infection (95\%) was noticed during January. Infected leaves were plastered with light brown to yellowish brown fruit bodies of the pathogen at the lower surface of the leaves. Severely infected plants showed premature defoliation. Harar trees growing at Advanced Centre for Rainfed Agriculture (ACRA), SKUAST-J, Dhiansar were noticed to be infected severely by several insect pests; major among them were the gall forming insects, scales and mealy bugs (Reena et al., 2017). Year round study was therefore conducted to identify the gall forming insect; one of the major insect pest. The losses inflicted by them, in terms of reduction in chlorophyll content, photosynthetic area; thereby resulting in economic loss was also assessed. Gall formation was noticed in approximately $30-40 \%$ of harad leaves on their underside during July. Curling of leaves also started along with the formation of galls. By the end of October, the galls attain their full size. All this greatly reduced the photosynthetic area and efficiency of leaves. On dissecting these galls at different stages of their formation, thrips were found inside.

\section{Genetic Studies}

Genetic transformation of Terminalia chebula Retz. was carried out by Shyamkumar et al. (2007) using Agrobacterium tumefaciens strain C-58. Explants such as cotyledon, hypocotyl, excised mature zygotic embryo, cotyledonary node, in vitro leaf and shoot were used for genetic transformation. Different experimental methods were followed for infecting the explants. Cotyledon and hypocotyl explants showed swelling response on MS basal medium subsequent to genetic transformation. About 32.5 $\pm 2.5 \%$ cultures showed swelling response when 8-12 d in vitro pre-cultured cotyledon explants were used. Swelling response was not observed in nontransformed control cotyledon explants. Callus induction was observed in one of the swollen cotyledon explants infected with the bacterial suspension grown on media containing $0.1 \mathrm{mM}$ acetosyringone. Callus initiation was not observed in cotyledon explants without co-cultivation, which were kept as control. The transformed callus was subjected to nopaline assay using paper electrophoresis. The analysis indicated the transformed nature of the callus with the presence of nopaline and its absence in non-transformed control callus. The transformed callus was analyzed for the presence of tannins using thin layer chromatography, which indicated the presence of tannic acid in the transformed callus. Verma et al. (2013) carried out in vitro regeneration of $T$. chebula to obtain complete plantlets from juvenile explants (hypocotyls and cotyledon). Dried seed were inoculated on MS medium after surface sterilization with Bavistin (0.2\%) alone and followed by $\mathrm{HgCl}_{2}(0.1 \%)$, resulted in maximum $(75 \%)$ germination. Hypocotyl showed $90 \%$ and cotyledon $75 \%$ callus induction on MS medium containing $1.0 \mathrm{mg} \mathrm{l}^{-1} 2,4-\mathrm{D}$ after 30 days of 
inoculation. Shoot regeneration was recorded only from cotyledonary callus on shoot induction medium comprising 1.5 $\mathrm{mg} \mathrm{l}^{-1}$ BAP with $10 \mathrm{mg} \mathrm{l}^{-1} \mathrm{NAA}$ with maximum (36.67\%) shoot regeneration. Maximum (43.75\%) rooting was reported in $1 / 2$ strength MS medium with $0.5 \%$ activated charcoal. Transgenic callus was produced through Agrobacterium tumifaciens mediated genetic transformation carrying gus and $n p t-I /$ gene from cotyledonary explants. Co-cultivation (72 h) proceeded by pre-conditioning ( $72 \mathrm{~h}$ ) was found best for callus induction. Successful integration of gus gene was reported. Ranjini et al. (2015) carried out a study which was aimed to reveal its genetic diversity based on molecular markers from twelve $T$. chebula accessions located at Herbal garden, Indian Institute of Horticultural Research, Bengaluru. Molecular diversity was studied using RAPD markers. A total of 8 polymorphic primers produced 314 polymorphic bands and 195 monomorphic bands. Unweighted Pair Group Method with Arithmetic Mean (UPMGA) dendrogram divided the accessions into 2 major clusters. Accession IIHRTC2 and IIHRTc10 showed maximum genetic diversity with $55 \%$ similarity. This characterization based on molecular markers will help in identification of economically useful accessions for further crop improvement programme. This genetic diversity analysis study in $T$. chebula using molecular markers will assist in conservation and further improvement of the species through breeding.

\section{Production and Marketing}

India is by far the main producing country of Harar. Production of dried fruits in India is estimated to be 100,000 tonnes of which $20 \%$ is exported to adjoining countries, Europe and U.S. (World Agroforestry Centre). Large sized fruits fetch higher price in the national and international markets and thus fruit size is an important characteristic. Harar freshly collected and dried immediately have yellowish color and fetch a better price. The demand for its fruit has increased tremendously, because of its medicinal value; its fruits are sold at a price of $₹ 10$ to $60 \mathrm{~kg}^{-1}$. The Harar produced in Morni Hills and the adjoining part of Haryana is in great demand in Pakistan, Afghanistan, Iran, Iraq and other Gulf countries. The Harar fruits are sold at two places (Khari Bawali in New Delhi and Majitha in Amritsar district) in North India. In South India, Coimbatore, Mumbai, Chennai, Nagpur, Bangalore and Indore are the major markets of Harar. Guleria et al. (2017) analyzed the Economics of Production of NTFPs: A case study of Harar (Terminalia chabula) in Himachal Pradesh, a sample of 40 farmers each from Sirmour and Kangra district of Himachal Pradesh. They found that the average establishment cost per year was ₹ $13550100^{-1}$ plants. The maintenance cost of grafted harar increased from $₹ 12241.78$ to $₹ 123675.30$ during $2^{\text {nd }}$ year to $15^{\text {th }}$ year and net returns varied from ₹ (-) 12241 to 116262 . The payback period worked out to be 9 years, NPV as ₹ 226106, the benefit-cost ratio as 1.57 and internal rate of return (IRR) as 33\% under the present value summation method.

\section{Problems/Constraints}

The poor germination capacity, lack of natural regeneration and knowledge regarding its propagation are the limiting factors for its adoption in Agroforestry systems. Further its cultivation in Agroforestry systems is constrained by lack of availability of superior selections. Other causes such as hard seed coat, seed predation, peak fruit fall coincided with post monsoon, etc. may also affect on regeneration (Bhardwaj and Chakaborty, 1994; Srivatsava, 2000). Fruits harvested from natural populations for commercial purpose may be one of the major causes for poor natural regeneration in T. chebula. The fruits when allowed to lie on the ground have darker color with sometimes mould attack. Tannin content in such decaying fruits is also very low. Mould attack also sometimes occurs on the tree and this is mentioned as the major cause of poor quality of myrobalans.

\section{Conclusion}

Due to commercial importance of $T$. chebula, several farmers have shown interest in bringing the species under cultivation. These farmers should be trained for vegetative propagation of improved varieties. Complete absence of natural regeneration of Harar in its natural population confirms the urgency of propagation of the species with the help of artificial techniques. Overall, the Government support is mandatory in terms of value addition and marketing of Harar to improve the economic growth and stability of the farmers.

\section{References}

Aher, V.D., Kumar, A., 2010. Immunomodulatory effect of alcoholic extract of Terminalia chebula ripe fruits. Journal of Pharma Sciences and Research 2, 539-544.

Ahn, M.J., Kim, C.Y., Lee, J.S., Kim, T.G., Kim, S.H., Lee, C.K., Lee, B.B., Shin, C.G., Huh, H., Kim, J., 2002. Inhibition of HIV-1 integrase by galloyl glucoses from Terminalia chebula and flavonol glycoside gallates from Euphorbia pekinensis. Planta Med 68, 457-459.

Bag, A., Bhattacharyya, S.K., Bharati, P., Pal, N.K., Chattopadhyay, R.R., 2009. Evaluation of antibacterial properties of Chebulic myrobalan (fruit of Terminalia chebula Retz.) extracts against methicillin resistant Staphylococcus aureus and trimethoprimsulphamethoxazole resistant uropathogenic Escherichia coli. African Journal of Plant Sciences 3, 25-29.

Bhardwaj, S.D., Chakraborty, A.K., 1994. Studies on time of seed collection, sowing and pre-sowing seed treatments of Terminalia bellirica Roxb. and Terminalia chebula Retz. Indian Forester 120, 430-439.

Burkill, H.M., 1985. The useful plants of west tropical Africa. $2^{\text {nd }}$ edition, Royal botanic garden, Kew richnd, United Kingdom 2, 960.

Daniel, M., 2005. Medicinal plants, chemistry and properties. Oxford and IBH Company Publishing Company Private Limited, New Delhi, 184-185. 
Dwivedi, S., 2008. Anthelmintic activity of alcoholic and aqueous extract of fruits of Terminalia chebula Retz. Ethnobot Leafl 12, 741-743.

Guleria, A., Tiwari, P., Sharma, R., 2017. Cost of cultivation and economic feasibility of grafted Harar (Terminalia chebula) In Himachal Pradesh. International Journal of Pure and Applied Biosciences 5, 1005-1011.

Israni, D.A., Patel, K.V., Gandhi, T.R., 2010. Anti-hyperlipidemic activity of aqueous extract of Terminalia chebula and Gaumutra in high cholesterol diet fed rats. International Journal of Pharma Sciences 1, 48-59.

Joshi, S.G., 2002. Medicinal plants. Oxford and IBH Company Publishing Limited, New Delhi, 141-146.

Joshie, P., Narain, P., 1992. Bhimal: a multipurpose tree for agroforestry. Indian Farming 41, 14-15

Joy, P.P., Thomas, J., Mathew, A., Sakira, P., 1998. Medicinal Plants. Kerala Agriculture University, 76.

Kannan, V.R., Rajasekar, G.S., Rajesh, P., Balasubramanian, V., Ramesh, N., Solomon, E.K., Nivas, D., Chandru, S., 2012. Antidiabetic activity on ethanolic extracts of fruits of Terminalia chebula Retz. Alloxan induced diabetic rats. American Journal of Drug Discover and Development 2, 135-142.

Khare, C.P., 2007. Indian Medicinal Plants- an illustrated dictionary. Springer- Verlag Berlin/Heidelburg, 651-656.

Kumar, M., Bhatt, V., 2006. Plant Biodiversity and Conservation of Forests in Foot Hills of Garhwal Himalaya. Lyonia: Journal of Ecology and Application 11, 43-59.

Mahesh, R., Ramesh, T., Nagulendran, K.R., Velavan, S., Hazeena, B.V., 2007. Effect of Terminalia chebula on monoamine oxidase and antioxidant enzyme activities in aged rat brain. Pharmacognosy Magazine 3, 12-16.

Mohan, V., Manokaran, P., 2005. Control of leaf rust of Terminalia chebula caused by Uredo terminallae. Indian Forester, 131.

Nair, V., Singh, S., Gupta, Y.K., 2010. Anti-arthritic and disease modifying activity of Terminalia chebula Retz. in experimental models. Journal of Pharmacy and Pharmacology 62, 1801-1806.

Ranjini, T.N., Bhanuprakash, K., Suryanarayana, M.A., Yamuna, B.G., 2015. Genetic diversity analysis using molecular marker in Terminalia chebula. Journal of Applied and Natural Science 7, 997-1000.

Reddy, B.D., Reddy, T., Jyotsna, G., Sharan, S., Priya, N., Lakshmipathi, V., Reddanna, P., 2009. Chebulagic acid, a COX-LOX dual inhibitor isolated from the fruits of Terminalia chebula Retz., induces apoptosis in COLO-205 cell line. Journal of Ethnopharmacology 124, 506-512.

Reddy, V.R.C., Kumari, S.R., Reddy, B.M., Azeem, M., Prabhakar, M., Rao, A.A., 1990. Cardiotonic activity of the fruits of Terminalia chebula. Fitoterapia 41, 517-525.
Reena, Tyagi, K., Sinha, B.K., Rai, P.K., 2017. Gall thrips infesting Terminalia chebula- One of the most important medicinal plants of Jammu and Kashmir, India. Ecology Environment and Conservation 23, 394-396.

Saleem, M., Sood, K.K., Singh, P., 2010. Producing quality planting stock of Terminalia chebula for integration in Agroforestry farms. APA News 36, 5-6.

Saleem, M., Sood, K.K., Gupta, S.K., Raina, N.S., Gupta, L.M., 2013. Effect of seed collection time and pre-treatment on germination, identification and vegetative propagation of superior germplasm of Terminalia chebula Retz.- A multipurpose Agroforestry tree. Range Management and Agroforestry 34, 162-170.

Sambamurty, A.V.S.S., 2005. Taxonomy of Angiosperms. K. International Pvt. Ltd. New Delhi, 366-711.

Sankanur, M., Singh, N.B., Thakur, S., Saresh, N.V., Verma, A., 2015. Phenological behaviour and reproductive characters of Terminalia chebula Retz., an important tree species for sustainable development of sub-tropical Himalayas. Journal of International Academic Research for Multidisciplinary 2, 5075-5083.

Sharma, K., Thakur, S., Badiyala, S.D., Sharma, N.K., 1995. First report on the propagation of Terminalia chebula Retz. through patch budding. The Indian Forester 121, 760-761.

Shyamkumar, B., Anjaneyulu., Giri, C.C., 2007. Genetic transformation of Terminalia chebula Retz. and detection of tannin in transformed tissue. Current Science 92, 361-367.

Singh, R.V., 1982. Fodder Trees of India. Oxford and IBH Publishing Co. Pvt. Ltd., New Delhi.

Srivastava, R.K., 2000. Approach Grafting- a New Approach for the formation of Clonal Bank of Terminalia chebula. The Indian Forester 126, 300-304.

Srivastava, R.K., 2000. Forest fire causing poor stocking of Santalum album and Terminalia chebula in Southern India. IFFN No.22, 28-30.

Tasduq, S., Singh, K., Satti, N., Gupta, D., Suri, K., Johri, R., 2006. Terminalia chebula (fruit) prevents liver toxicity caused by sub-chronic administration of rifampicin, isoniazid and pyrazinamide in combination. Human and Experimental Toxicology 25, 111-118.

Trivedi, K.P., 2008. Vanaushadhi Visheshank. Part-I. Dhanvantari, Aligarh.

Verma, Y.S, Kanwar, K., Bhardwaj, S.V., 2013. Regeneration and transformation studies in Terminalia chebula Retz. Journal of Scientific and Industrial Research 72, 563-571. 